\title{
Active Mechanical Vibration Control of Rotary Compressors for Air-conditioning Systems
}

\author{
Cheon-Su Park ${ }^{*}$, SeHwan Kim ${ }^{* *}$, Gwi-Geun Park ${ }^{*}$, and Jul-Ki Seok ${ }^{\dagger}$ \\ *Air Conditioning and Energy Solution Control R\&D Lab, LG Electronics Inc., Changwon, Korea \\ $\dagger^{* * *}$ Power Conversion Lab., Dept. of Electrical Eng., Yeungnam University, Gyeongsan, Korea
}

\begin{abstract}
Recent power electronics and variable-frequency motor drive technologies have been applied to air conditioners to improve efficiency and power density. However, the mechanical vibrations and acoustic noise resulting from the compressor still remain as a serious problem. This paper presents the development and implementation of an online disturbance state-filter for the suppression of multiple unknown and time-varying vibrations of air conditioning systems. The proposed design has a form of the state-filter based on a Luenburger-style closed-loop speed observer. An active vibration decoupling strategy with an estimated disturbance is provided, which manipulates a motor torque command. Since the proposed estimation does not require any additional transducers or hardware for obtaining real-time information upon disturbances, it is suitable for retrofitting industrial air conditioners.
\end{abstract}

Key words: Acoustic noise, Active vibration decoupling strategy, Mechanical vibrations, Online disturbance state-filter, Rotary compressor, Variable-frequency air conditioning systems

\section{INTRODUCTION}

Many different types of compressors have been invented over the years for air conditioning systems: reciprocating, rotary, centrifugal, screw, and scroll compressors [1]. Among them, low cost and high efficiency rotary compressors have been commonly used in in-room type air conditioners as shown in Fig. 1 [1]-[3].

In a rotary compressor, the refrigerant is compressed by the rotating action of a roller inside a cylinder, as shown in Fig. 2. The roller rotates eccentrically (off-centre) around a shaft so that part of the roller is always in contact with the inside wall of the cylinder. At a certain point in the rotation of the roller, the intake port is exposed and a quantity of refrigerant is sucked into the cylinder, filling one of the sealed areas. As the roller continues to rotate the volume of the area the refrigerant occupies is reduced and the refrigerant is compressed. When the exhaust valve is exposed, the high-pressure refrigerant

Manuscript received Mar. 28, 2012; revised Aug. 20, 2012

Recommended for publication by Associate Editor Marian P. Kazmierkowski. ${ }^{\dagger}$ Corresponding Author: doljk@ynu.ac.kr

Tel: +82-53-810-2484, Fax: +82-53-810-4767, Yeungnam University

*Air Conditioning and Energy Solution Control R\&D Lab, LG

Electronics Inc., Korea

Power Conversion Lab., Dept. of Electrical Eng., Yeungnam University, Korea forces the exhaust valve to open and the refrigerant is released. Rotary compressors are efficient because the actions of taking in and compressing refrigerant occur simultaneously. However, the eccentric rotation of a rotary compressor produces significant vibrations and noise that are not allowed in indoor environments and may crack the suction pipes by lasting pulsations [4], [5].

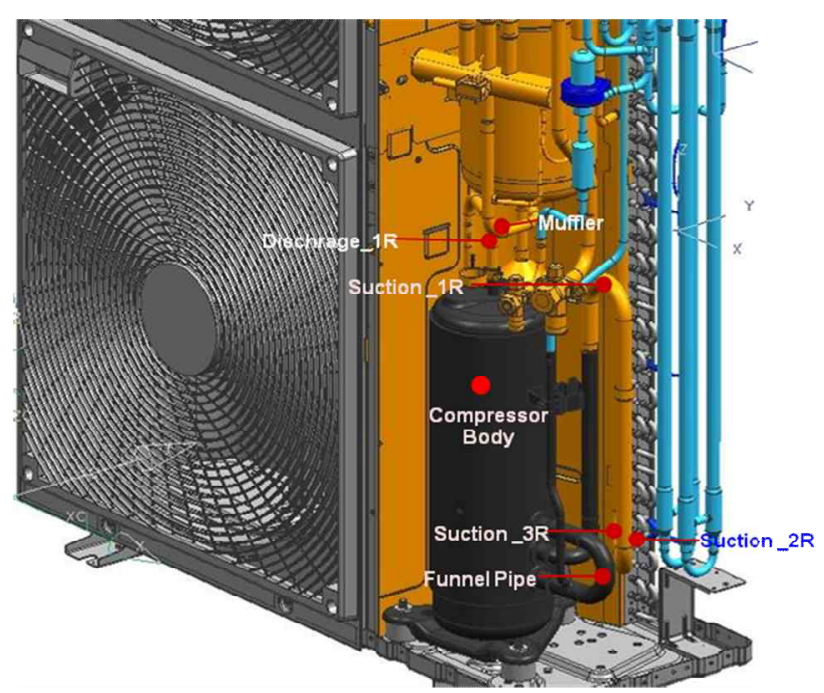

Fig. 1. Schematic layout of an air conditioner with a rotary cylinder compressor. 


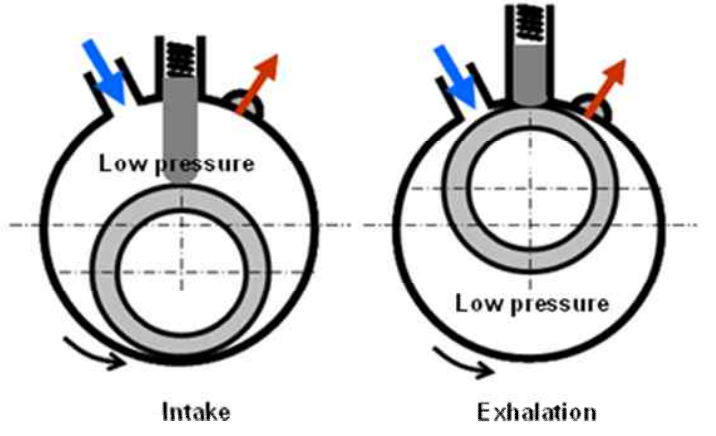

Fig. 2. Rotary compressor operation.

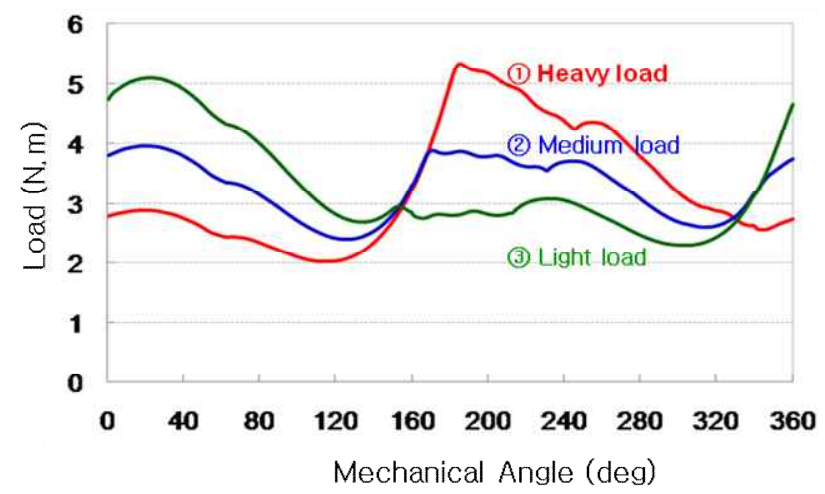

Fig. 3. Typical compressor load profiles over one mechanical rotation.

Fig. 3 shows a typical rotary compressor torque profile with the external load over one mechanical rotation.

In the last decade, variable-frequency motor drives (VFMDs) have made the electrical assist of rotary compressors a realistic candidate for energy savings and increased comfort [6]. In particular, interior permanent-magnet synchronous motors (IPMSMs) have received a great deal of attention in the field of compressor drive applications because of their unique features, such as high efficiency, high power density, and a wide constant power speed range [5], [7]. While most VFMD research has been focused on framework improving energy savings and designing motor topologies [8-10], vibration suppression control techniques have not been discussed to the same degree.

In the academic environments, a few articles are available that discuss multivariable feedback control [11] and model reference adaptive control [12]. Nevertheless, the industry tends to be reluctant to use these modern control methodologies due to their relative complexity and small performance improvements.

Resonant controllers [13], [14] have been proposed for torque ripple reduction in ac motors as an alternative to more complex non-linear regulators. This type of controller provides zero steady-state errors at harmonic frequencies due to their infinite gain in an open-loop. However, the cut-off frequency adaptation and controller gain selection are not trivial as the torque ripple amplitude changes with the temperature and load conditions.

Industrial experience has shown that a look-up table-based control concept, which can impose the compensation profiles matching the compressor torque curves shown in Fig. 3, is effective in suppressing mechanical vibrations and increasing reliability. Multi-dimensional or numerous look-up tables are required to cover the entire fluctuation torque space with the load conditions. Therefore, using look-up tables for vibration decoupling has some limitations. First, the amount of information that needs to be stored is not obvious because of the nonlinearity of the curves. In addition, this results in a reliance on large memories and time-consuming tests to build-up maps. Moreover, heavy dependence on look-up tables-based compensation is often undesirable as the profile has a time-varying property due to temperature changes and the mechanical aging process.

The major contribution of this paper is the development and integration of an online disturbance state-filter for the suppression of multiple unknown and time-varying vibrations in IPMSM-based variable-frequency air conditioning systems. The proposed design has a form of the state-filter based on a Luenburger-style closed-loop rotor speed observer. An active vibration decoupling strategy with the estimated disturbance is provided, where the motor itself acts like a vibration damper. The designed state-filter only requires information on the system's moment of inertia. State-filter estimation accuracy in the presence of the phase lag from the position sensorless operation is discussed. A comprehensive collection of experiments are used to evaluate and verify the feasibility of the presented idea.

\section{ANALYSIS AND DESIGN OF STATE-FILTERS FOR DISTURBANCE ESTIMATION}

In frequency-variable air condition systems, a familiar proportional-integral (PI) type speed controller drives the IPMSM rotor speed $\Omega_{\mathrm{r}}$ to follow a given speed command $\Omega_{\mathrm{r}}^{*}$, as shown in Fig. 4. A torque (or current) controller regulates the motor torque $\mathrm{T}_{\mathrm{e}}$ that tracks the torque command $\mathrm{T}_{\mathrm{e}}^{*}$ based on the current feedback. Here, $\mathbf{V}_{\mathrm{dq}}^{\mathrm{r}}$ and $\mathbf{I}_{\mathrm{dq}}^{\mathrm{r}}$ are the $\mathrm{d}-\mathrm{q}$ axis stator voltage and current vector in the rotor reference frame, respectively, $\mathrm{R}_{\mathrm{S}}$ represents the stator resistance, $\Theta_{r}$ is the electrical rotor angle, $J_{p}$ denotes the system moment of inertia, $\mathrm{K}_{\mathrm{T}}$ is the motor torque constant, and $\mathbf{J}=\left[\begin{array}{cc}0 & -1 \\ 1 & 0\end{array}\right]$. In this paper, the superscript “*” indicates a command variable while the symbol " $\wedge$ " is used to denote an estimated one. 


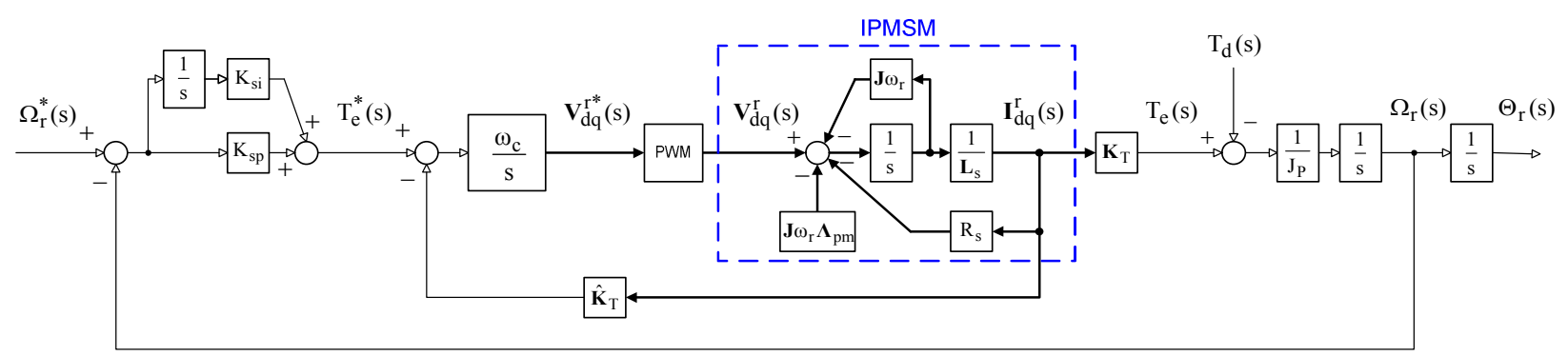

Fig. 4. Control structure of an IPMSM drive in air conditioning systems.

The stator inductance and the magnet flux linkage can be defined by:

$$
\mathbf{L}_{\mathrm{s}}=\left[\begin{array}{cc}
\mathrm{L}_{\mathrm{d}} & 0 \\
0 & \mathrm{~L}_{\mathrm{q}}
\end{array}\right] \text { and } \boldsymbol{\Lambda}_{\mathrm{pm}}=\left[\begin{array}{c}
\lambda_{\mathrm{pm}} \\
0
\end{array}\right]
$$

where $\mathrm{L}_{\mathrm{dq}}$ represents the $\mathrm{d}-\mathrm{q}$ axis stator inductance and $\lambda_{\mathrm{pm}}$ is the flux linkage of the permanent magnet (PM). $\mathrm{K}_{\mathrm{sp}}$ and $\mathrm{K}_{\mathrm{si}}$ are the PI speed control gains, respectively, and $\omega_{c}$ is a torque (or current) control bandwidth that is sufficiently higher than that of the rotor speed control. The cascaded speed-current control scheme is advantageous because the bandwidth of each loop can be specified explicitly from the inner loop to the outer loop. Here, the load torque resulting from the rotary compressor is considered as an external disturbance $T_{d}$, which considerably disturbs the rotor speed regulation. The argument $(s)$ indicates that the analysis was done in the $s$-domain.

\section{A. Design and Analysis of Rotor Angle-based State-Filters}

Fig. 5 shows a block diagram of a load torque disturbance estimation strategy employing a closed-loop enhanced Luenberger-style rotor angle observer [15-16].

The closed-loop transfer function of the rotor angle estimation can be obtained as:

$$
\frac{\hat{\Theta}_{r}}{\Theta_{r}}=\frac{J_{p} s^{3}+b_{o} s^{2}+K_{s o} s+K_{i o}}{\hat{J}_{p} s^{3}+b_{o} s^{2}+K_{s o} s+K_{i o}}
$$

where $\mathrm{K}_{\mathrm{io}}, \mathrm{K}_{\mathrm{so}}$, and $\mathrm{b}_{\mathrm{o}}$ represent the observer gains, and $\hat{J}_{\mathrm{p}}$ is the estimated inertia used in the observer. Zero lag properties can be achieved in the rotor angle estimation because the stator current feedback $I_{d q}$ is fed-forward to the observer as the estimated motor torque $\hat{\mathrm{T}}_{\mathrm{e}} \quad$ [16].

The observer characteristic polynomial of (2), taken from a triple eigenvalue, leads to the observer gains as:

$$
\begin{gathered}
\mathrm{b}_{\mathrm{o}}=-3 \hat{\mathrm{J}}_{\mathrm{p}} \omega_{\mathrm{ob}}, \quad \mathrm{K}_{\mathrm{so}}=3 \hat{\mathrm{J}}_{\mathrm{p}} \omega_{\mathrm{ob}}^{2}, \\
\mathrm{~K}_{\mathrm{io}}=-\hat{\mathrm{J}}_{\mathrm{p}} \omega_{\mathrm{ob}}^{3}
\end{gathered}
$$

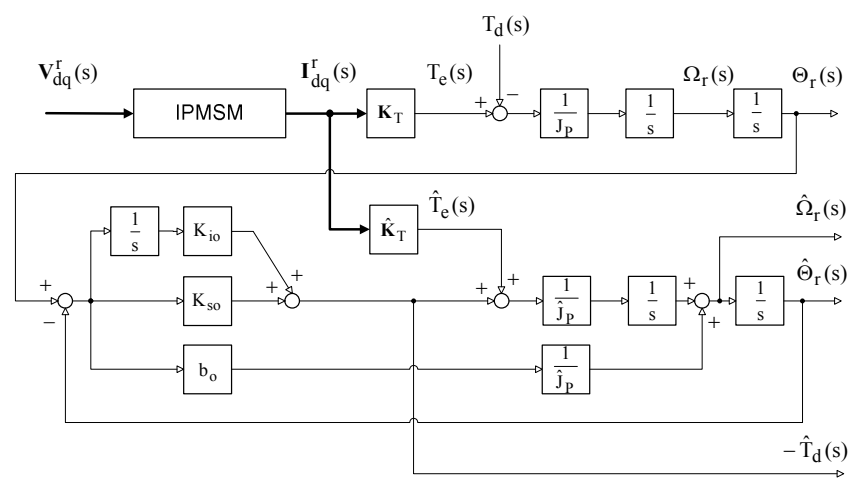

Fig. 5. Disturbance torque estimation based on rotor angle observer.

where $\omega_{\mathrm{ob}}$ is an observer eigenvalue.

The rotor angle tracking observer has been also adopted to estimate the time-varying disturbance $\hat{T}_{d}$, resulting from the rotary compressor, at the output of the observer controller, as shown in Fig. 5. The transfer function of the disturbance estimation is:

$$
\frac{\hat{\mathrm{T}}_{\mathrm{d}}}{\mathrm{T}_{\mathrm{d}}}=\frac{\mathrm{K}_{\mathrm{so}} \mathrm{s}+\mathrm{K}_{\mathrm{io}}}{\hat{\mathrm{J}}_{\mathrm{p}} \mathrm{s}^{3}+\mathrm{b}_{\mathrm{o}} \mathrm{s}^{2}+\mathrm{K}_{\mathrm{so}} \mathrm{s}+\mathrm{K}_{\mathrm{io}}} .
$$

Fig. 6 is a frequency plot of (4) assuming no parameter errors. Here, the closed-loop eigenvalues are set at $500 \mathrm{~Hz}$. Unlike the rotor angle observer with zero lag properties, the estimation of the disturbance torque has a state-filter trajectory with lagging properties.

It can be seen from Fig. 5 that the disturbance torque is estimated from the angle information that is filtered out by the double integration. This implies that the rotor speed information is more suitable for improving the estimation dynamics than the rotor angle information. To make this more precise, the rotor speed-based state-filter is examined for enhanced disturbance torque estimation. 

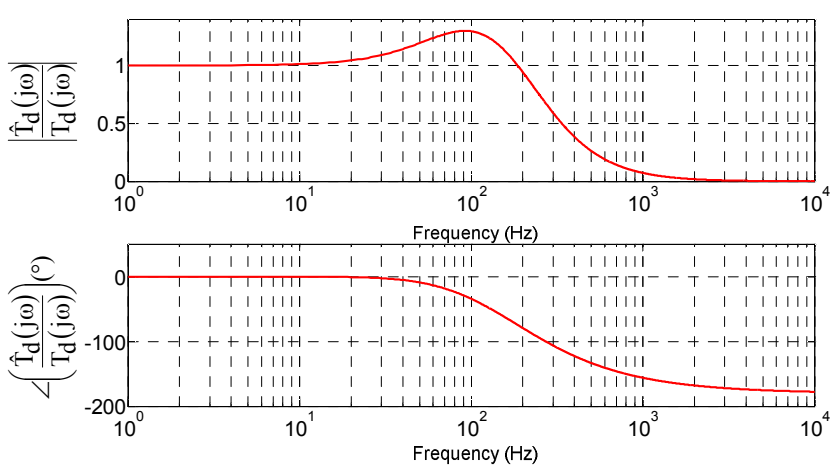

Fig. 6. Frequency response of of the disturbance torque estimation based on rotor angle observer.

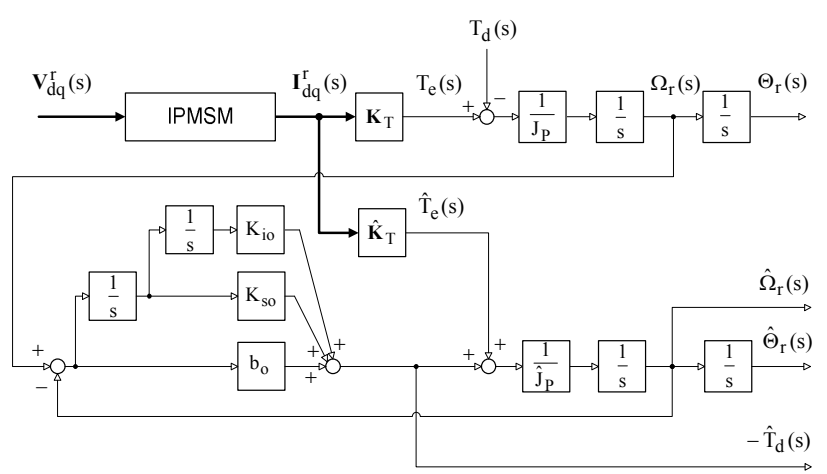

Fig. 7. Disturbance torque estimation based on rotor speed observer.

\section{B. Design and Analysis of Rotor Speed-based State-Filters}

Fig. 7 shows a block diagram of a load torque disturbance estimation strategy employing a closed-loop rotor speed observer. The closed-loop transfer function of the rotor speed observer has a form identical to (2) as:

$$
\frac{\hat{\Omega}_{\mathrm{r}}}{\Omega_{\mathrm{r}}}=\frac{\mathrm{J}_{\mathrm{p}} \mathrm{s}^{3}+\mathrm{b}_{\mathrm{o}} \mathrm{s}^{2}+\mathrm{K}_{\mathrm{so}} \mathrm{s}+\mathrm{K}_{\mathrm{io}}}{\hat{\mathrm{J}}_{\mathrm{p}} \mathrm{s}^{3}+\mathrm{b}_{\mathrm{o}} \mathrm{s}^{2}+\mathrm{K}_{\mathrm{so}} \mathrm{s}+\mathrm{K}_{\mathrm{io}}} .
$$

In contrast, the closed-loop transfer function of the rotor speed-based state-filter is given by:

$$
\frac{\hat{\mathrm{T}}_{\mathrm{d}}}{\mathrm{T}_{\mathrm{d}}}=\frac{\mathrm{b}_{\mathrm{o}} \mathrm{s}^{2}+\mathrm{K}_{\mathrm{so}} \mathrm{s}+\mathrm{K}_{\mathrm{io}}}{\hat{\mathrm{J}}_{\mathrm{p}} \mathrm{s}^{3}+\mathrm{b}_{\mathrm{o}} \mathrm{s}^{2}+\mathrm{K}_{\mathrm{so}} \mathrm{s}+\mathrm{K}_{\mathrm{io}}}
$$

where the numerator has a $2^{\text {nd }}$-order term that improves the higher frequency estimation accuracy more than that of the rotor angle observer.

Fig. 8 shows the frequency response of the disturbance estimation accuracy of the rotor speed-based state-filter. Comparing Fig. 6 and Fig. 8 verifies that the rotor speed-based state-filter can improve the high frequency disturbance estimation.

By combining (3) and (6), the closed-loop transfer function
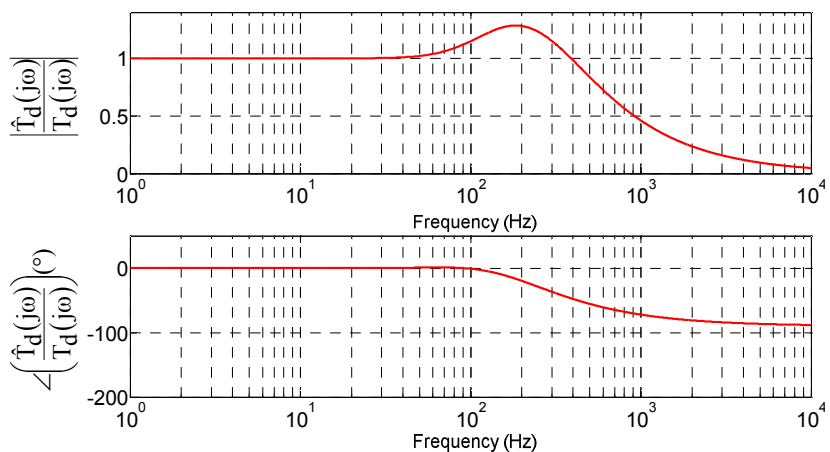

Fig. 8. Frequency response of of the disturbance torque estimation based on rotor speed observer.

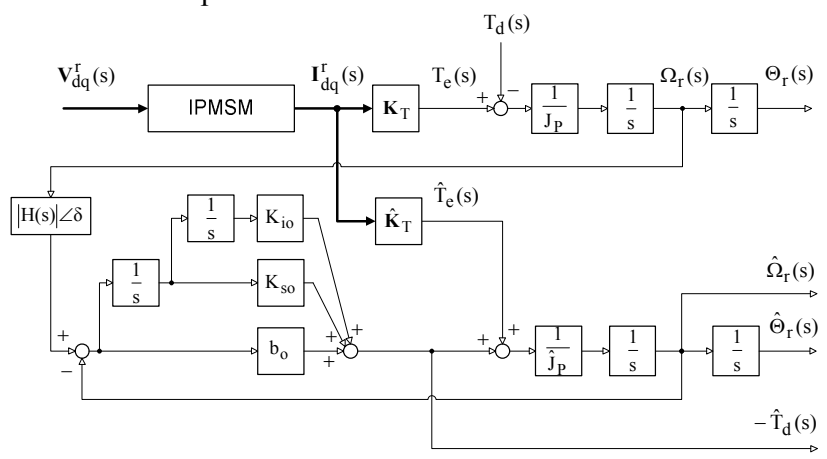

Fig. 9. Rotor speed-based state-filter considering sensorless operation.

of (6) can be rewritten as:

$$
\frac{\hat{\mathrm{T}}_{\mathrm{d}}}{\mathrm{T}_{\mathrm{d}}}=\frac{-3 \omega_{\mathrm{ob}} \mathrm{s}^{2}+3 \omega_{\mathrm{ob}}^{2} \mathrm{~s}-\omega_{\mathrm{ob}}^{3}}{\mathrm{~s}^{3}-3 \omega_{\mathrm{ob}} \mathrm{s}^{2}+3 \omega_{\mathrm{ob}}^{2} s-\omega_{\mathrm{ob}}^{3}} .
$$

This means that the proposed disturbance estimation is completely insensitive to mechanical inertia errors. Thus, within the bandwidth of the observer, parameter insensitive disturbance torque estimates are available.

\section{Considerations of Position Sensorless Operation}

In today's VFMD air conditioning systems, back-EMF tracking-based position sensorless control technology has been widely employed for increasing reliability and reducing cost [11]. Thus, accurate disturbance identification is precluded due to the additional dynamics resulting from the position sensorless operation. To investigate the influence of position sensorless control on disturbance torque estimation, an equivalent speed sensorless block $\mathrm{H}(\mathrm{s})(=|\mathrm{H}(\mathrm{s})| \angle \delta)$ is inserted between the rotor speed reading channel and the observer, as shown in Fig. 9.

The transfer function of the disturbance is obtained by: 


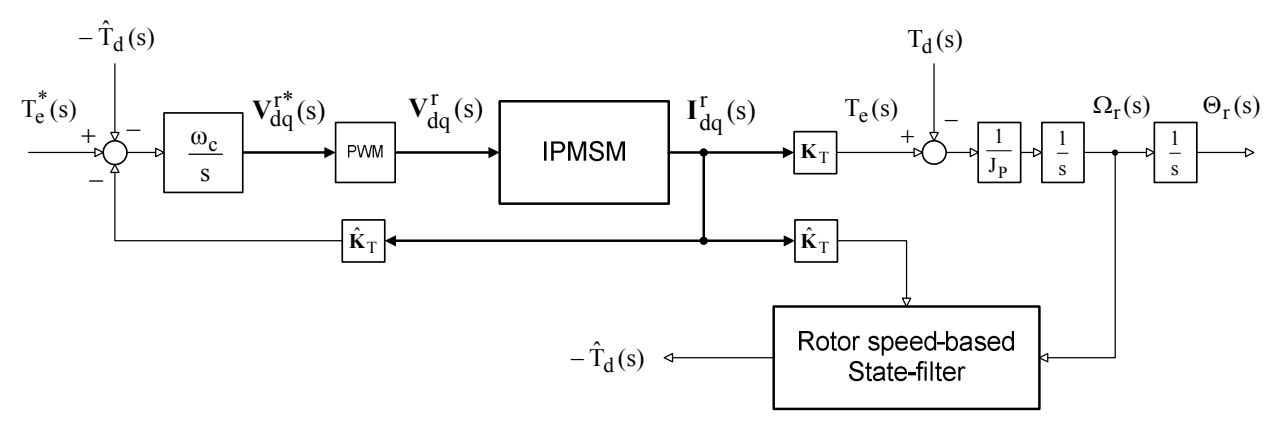

Fig. 10. The proposed estimation and compensation approach for active vibration control.

$$
\begin{aligned}
\hat{\mathrm{T}}_{\mathrm{d}}(\mathrm{s})= & \frac{\mathrm{b}_{\mathrm{o}} \mathrm{s}^{2}+\mathrm{K}_{\mathrm{so}} \mathrm{s}+\mathrm{K}_{\mathrm{io}}}{\hat{\mathrm{J}}_{\mathrm{p}} \mathrm{s}^{3}+\mathrm{b}_{\mathrm{o}} \mathrm{s}^{2}+\mathrm{K}_{\mathrm{so}} \mathrm{s}+\mathrm{K}_{\mathrm{io}}} \cdot \mathrm{T}_{\mathrm{d}} \\
& -\frac{\hat{\mathrm{J}}_{\mathrm{p}}\left(\mathrm{b}_{\mathrm{o}} \mathrm{s}^{3}+\mathrm{K}_{\mathrm{so}} \mathrm{s}^{2}+\mathrm{K}_{\mathrm{io}} \mathrm{s}\right)}{\hat{\mathrm{J}}_{\mathrm{p}} \mathrm{s}^{3}+\mathrm{b}_{\mathrm{o}} \mathrm{s}^{2}+\mathrm{K}_{\mathrm{so}} \mathrm{s}+\mathrm{K}_{\mathrm{io}}} \cdot(\mathrm{H}(\mathrm{s})-1) \cdot \Omega_{\mathrm{r}}(\mathrm{s}) \\
= & \frac{\mathrm{b}_{\mathrm{o}} \mathrm{s}^{2}+\mathrm{K}_{\mathrm{so}} \mathrm{s}+\mathrm{K}_{\mathrm{iso}}}{\hat{\mathrm{J}}_{\mathrm{p}} \mathrm{s}^{3}+\mathrm{b}_{\mathrm{o}} \mathrm{s}^{2}+\mathrm{K}_{\mathrm{so}} \mathrm{s}+\mathrm{K}_{\mathrm{io}}} \cdot \mathrm{T}_{\mathrm{d}} \\
& +\frac{\hat{\mathrm{J}}_{\mathrm{p}}\left(\mathrm{b}_{\mathrm{o}} \mathrm{s}^{3}+\mathrm{K}_{\mathrm{so}} \mathrm{s}^{2}+\mathrm{K}_{\mathrm{io}} \mathrm{s}\right)}{\hat{\mathrm{J}}_{\mathrm{p}} \mathrm{s}^{3}+\mathrm{b}_{\mathrm{o}} \mathrm{s}^{2}+\mathrm{K}_{\mathrm{so}} \mathrm{s}+\mathrm{K}_{\mathrm{io}}} \cdot\left(\Omega_{\mathrm{r}}(\mathrm{s})-\hat{\Omega}_{\mathrm{r}}(\mathrm{s})\right)
\end{aligned}
$$

It can be observed from (8) that the disturbance estimation depends on the sensorless control accuracy. At low speeds, the foremost inaccuracy of the back-EMF tracking-based sensorless control is a result of the phase lag due to the low pass filtering process rather than the estimated magnitude error [16]. Thus this phase shift effect should be compensated to avoid secondary upsets in the proposed estimation performance.

Fig. 10 shows an overall control block diagram of the proposed scheme to compensate compressor vibration. Here, the estimated disturbance torque in (6) is added to the torque command in a feedforward manner, which automatically adjusts the effective torque command. Thus this design can be effective for accurately estimating and compensating vibrations while reducing the computational complexity.

\section{EXPERIMENTAL RESULTS}

The proposed algorithm was implemented on a $7 \mathrm{~kW}$ rotary compressor-type air conditioner, as shown in Fig. 11.

The two phase current of the position sensorless-controlled IPMSM [17], as described in Table I, was sampled at $200 \mu \mathrm{s}$ and the dc link voltage was set to $540 \mathrm{~V}$. The online state-filter was performed every $200 \mu$ s, and the UV-15 vibration sensors from Rion Co. with an accuracy of $\pm 5 \%$ were mounted on suction pipes to assess the vibration mitigation. The observer eigenvalues were set to $500 \mathrm{~Hz}$ and the phase lag of the sensorless operation was evaluated before start-up and
TABLE I

RATINGS AND KNOWN PARAMETERS OF 7KW IPMSM

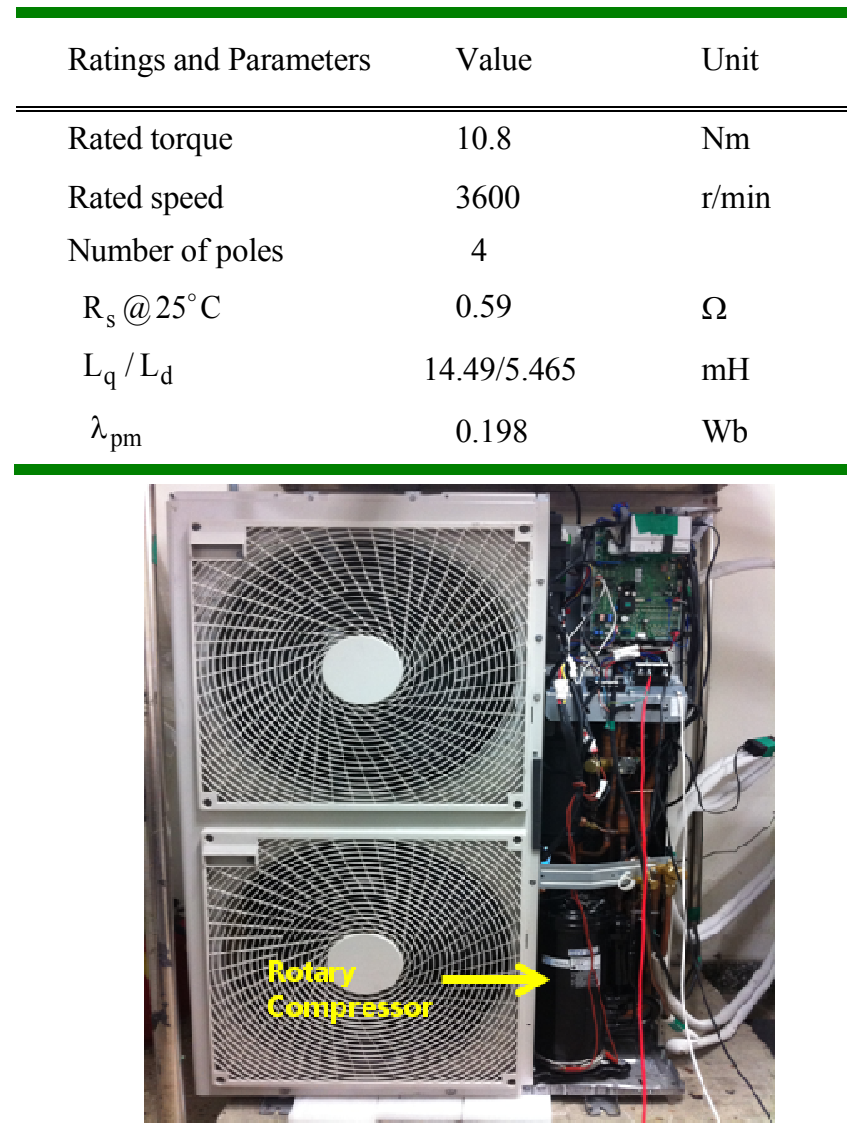

Fig. 11. Air conditioner under testing.

compensated with the rotor speed.

Fig. 12 shows standard test results with the speed feedback control alone when the motor is moving at a $1320 \mathrm{r} / \mathrm{min}$ speed command. From the top, the speed ripple (yellow), the electrical angle (red), the A-phase current (blue), and the B-phase current (green) are depicted.

The same test was repeated, under the proposed active vibration control, as shown in Fig. 13. Using the online compensation scheme, a $58.6 \%$ reduction in the root-mean square speed ripple can be achieved without using complicated look-up tables. 


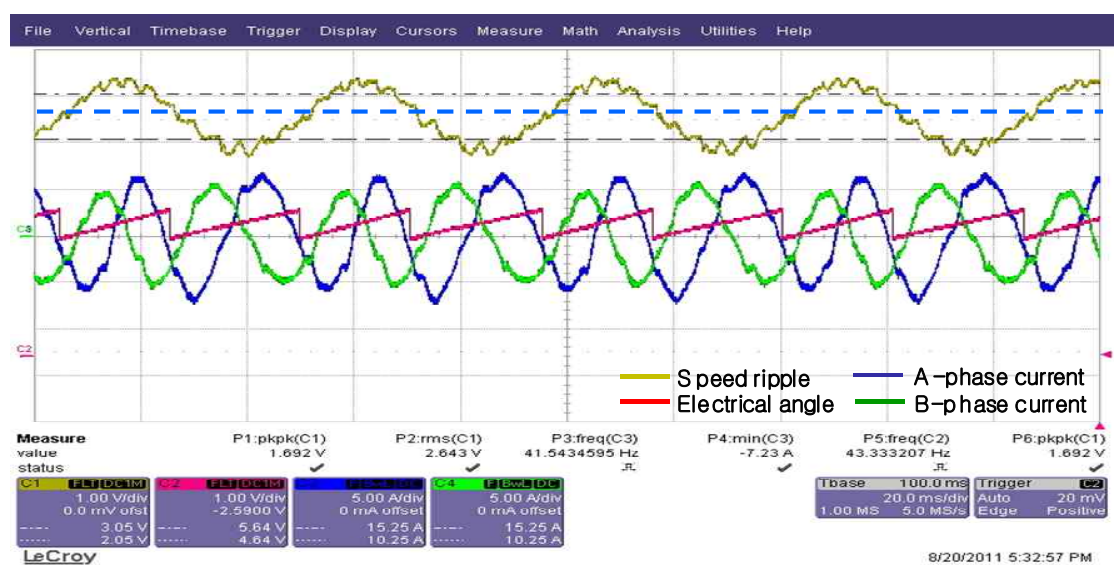

Fig. 12. Standard speed control performance. (Speed ripple $[120 \mathrm{r} / \mathrm{min} / \mathrm{div}]$, Electrical angle [ $3 \pi \mathrm{rad} / \mathrm{div}]$, A-phase current [5 A/div], B-phase current [5 A/div], Time [20ms/div]).

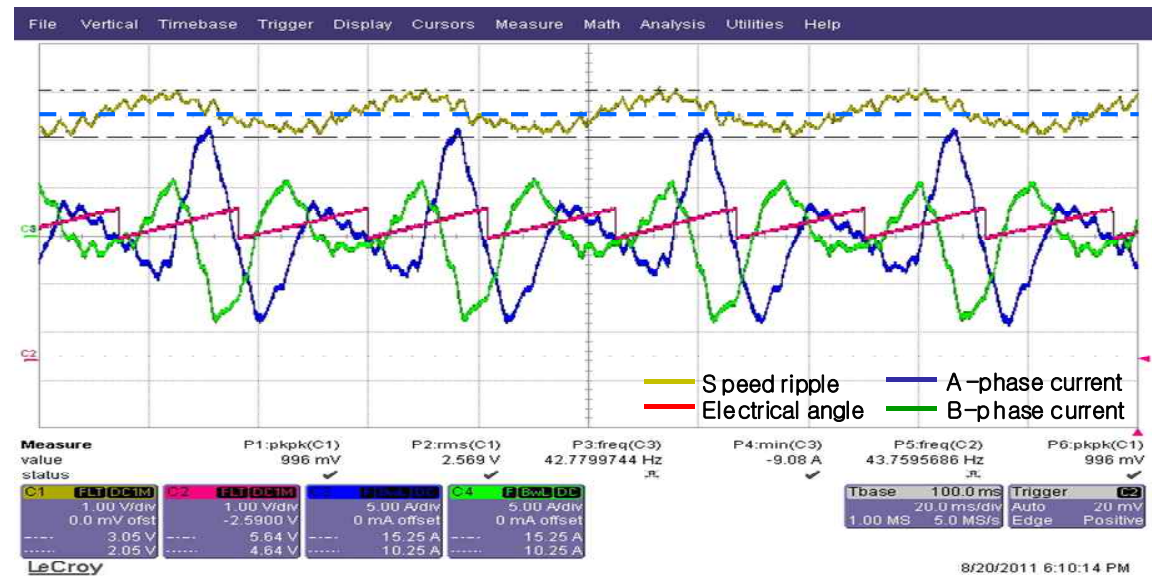

Fig. 13. Speed control performance with the proposed active vibration control. (Speed ripple [120 r/min/div], Electrical angle [3$\pi \mathrm{rad} / \mathrm{div}$ ], A-phase current [5 A/div], B-phase current [5 A/div], Time [20ms/div]).

An effective torque command fedforward of $\hat{\mathrm{T}}_{\mathrm{d}}$ adjusts the generated torque that makes the phase current have a distorted waveform to reject the estimated disturbance. Hence the proposed algorithm anticipates disturbances and so yields well-behaved speed responses.

Fig. 14 illustrates the summarized results in terms of speed ripples and vibration measurement tests for both the standard feedback control alone and the proposed compensation method. It can be seen that a remarkable improvement was achieved with the proposed state-filter at low speeds. The compensation effect vanishes over a speed of $2100 \mathrm{r} / \mathrm{min}$ because the mechanical system inertia becomes more dominant in this speed region. Thus the active vibration control is suspended over a speed of $2100 \mathrm{r} / \mathrm{min}$ in the target air conditioning system. From this result, it can be concluded that the vibration and the acoustic noise of the closed-loop system control are greatly improved by the proposed scheme while reducing the computational complexity. This is considered to be a very significant performance improvement by air conditioning system manufacturers.
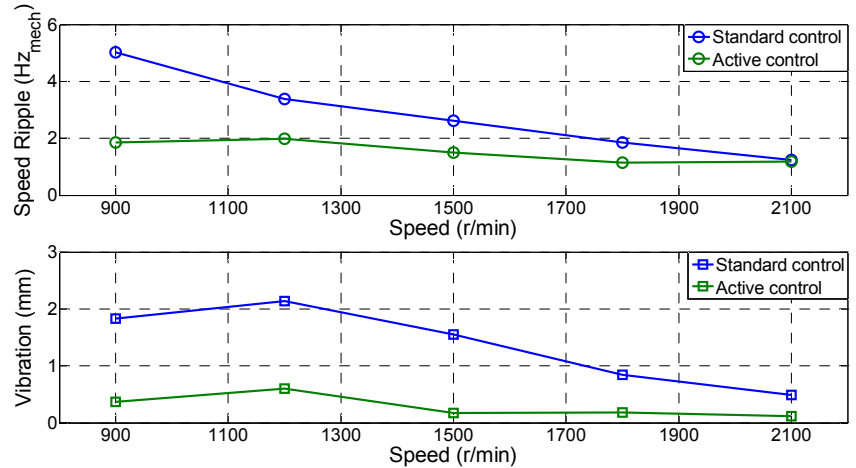

Fig. 14. Measurement results showing the compensation effect in terms of speed ripple and vibration.

\section{CONCLUSIONS}

This paper proposes an online disturbance state-filter for the suppression of multiple unknown and time-varying vibrations of position sensorless-controlled variable-frequency air conditioning systems. The proposed design has a form of the state-filter based on a closed-loop rotor speed observer. A state 
observer with speed dependent dynamics is used to estimate the load torque disturbance errors. By utilizing frequency response plots, the estimation accuracy is analyzed. Based on the analysis and measurements, the proposed active control was found to be very effective for reducing the decoupling noise and vibrations resulting from a rotary compressor without requiring any extra sensors. This suggests an accurate disturbance rejection methodology that does not sacrifice implementation simplicity. The main idea can be extended for compensating the unknown torque disturbances of modern ac drives.

\section{ACKNOWLEDGMENT}

This research was supported by 2011 Yeungnam University research grants.

\section{REFERENCES}

[1] J. Hodge, "Industrial uses of rotary compressors," Production Engineers Journal, Vol. 37, No. 8, pp. 490-499, 1958.

[2] LG Air Conditioner Rotary Compressor. [Online] http://www.lg.com/global/products/components/compress or/aircon-compressor/twin-rotary-compressor.jsp.

[3] M. Noguchi, K. Sano, and S. Takeshita, "Cavity resonance and noise reduction in a rotary compressor," IEEE Trans. Ind. Appl., Vol. IA-19, No. 6, pp. 1118-1123, Nov./Dec. 1983.

[4] S. M. Hwang, H. J. Lee, T. S. Lim, Y. H. Jung, and J. P. Hong, "The influence of electromagnetic force upon the noise of an IPM motor used in a compressor," IEEE Trans. Magn., Vol. 42, No. 10, pp. 3494-3496, Oct. 2006.

[5] A. M. Jungreis and A. W. Kelley, "Adjustable speed drive for residential applications," IEEE Trans. Ind. Appl., Vol. 31, No. 6, pp. 1315-1322, Nov./Dec. 1995.

[6] S. R. Macminn and T.M. Jahns, "Control techniques for improved high-speed performance of interior PM synchronous motor drives," IEEE Trans. Ind. Appl., Vol. 27, No. 5, Sep./Oct. 1991.

[7] S. Wang, J. Kang, and J. Noh, "Topology optimization of a single-phase induction motor for rotary compressor," IEEE Trans. Magn., Vol. 40, No. 3, pp. 1591-1596, May 2004.

[8] K. I. Tsai and C. C. Tsai, "A coordinate control approach for energy saving of central variable- frequency air conditioning systems," in Proc. IEEE-ICIEA Conf., pp. 2064-2069, 2010.

[9] S. Singh and B. Singh, "A voltage controlled PFC Cuk converter based PMBLDCM drive for air-conditioners," IEEE Trans. Ind. Appl., Vol. 48, No. 2, pp. 832-838, Mar./Apr. 2012.

[10] X. He, S. Liu, and H. Asada, "Multivariable feedback design for regulating vapor compression cycles," in Proceeding of American Control Conf., pp. 4331-4335, 1995.

[11] M. Zhang, Y. Li, T. Zhao, Z. Liu, and L. Huang, "A speed fluctuation reduction method for sensorless PMSM-compressor system," in Proc. IEEE-IECON, pp. 1633-1637, 2005.

[12] D. G. Luenberger, "An introduction to observers," IEEE Trans. Autom. Control, Vol. AC-16, No. 6, pp. 596-602, Dec. 1971
[13] H. Nagase, T. Okuyama, J. Takahashi, and K. Saitoh, "A method for suppressing torque ripple of an AC motor by current amplitude control," IEEE Trans. Ind. Electron., Vol.36, No.4, pp.504-510, Nov. 1989.

[14] J. Zeng, P. Degobert, and J.P. Hautier, "Minimum torque ripple control of permanent magnet synchronous motor in the stationary reference frame," in Proc. IEEE-IEMDC, pp. $667-673,2005$

[15] H. B. Kim, M. C. Harke and R. D. Lorenz, "Sensorless control of interior permanent magnet machine drives with zero-phase lag position estimation," IEEE Trans. Ind. Appl., Vol.39, No.6, pp.1726-1733, Nov./Dec. 2003.

[16] C. H. Choi, B. S. Kim, Y. K. Lee, J, H. Jung, and J. K. Seok, "Experimental evaluation of position sensorless control on hybrid electric vehicle applications," Journal of Power Electronics, Vol. 11, No. 4, pp. 464-470, Jul. 2011.

[17] S. Morimoto, K. Kawamoto, M. Sanada, and Y. Takeda, "Sensorless control strategy for salient-pole PMSM based on extended EMF in rotating reference frame", IEEE Trans. Ind. Appl., Vol. 38, No. 4, pp. 1054-1061, Jul./Aug. 2002.

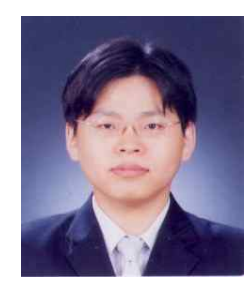

Cheon-Su Park received his B.S. in Computer Engineering from Konkuk University, Seoul, Korea, in 2005, and his M.S. in Electrical Engineering from Kyongbuk University, Daegu, Korea, in 2012. Since 2005 , he has been working as a Senior Research Engineer for LG Electronics Inc. His current research interests inlclude motor drives and the control of electrical machines, power converters, and inverter air conditioners.

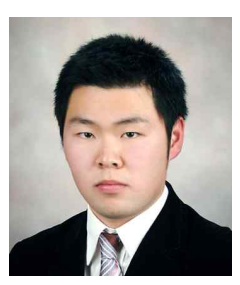

SeHwan Kim received his B.S. in Electrical Engineering from the School of Electrical Engineering, Yeungnam University, Gyeongsan, Korea, in 2010, where he is currently working toward a combined M.S.Ph.D. in the Power Conversion Laboratory. His current research interests include high performance electrical machine drives, battery voltage maximum utilization for EVs/HEVs, and precise torque control of interior PM synchronous motors.

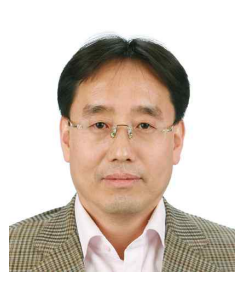

Gwi-Geun Park received his B.S in Electronics Engineering from the Kyungnam University, Kyungnam, Korea, in 1990, and his M.S. and Ph.D. from the Department of Intelligent Machinery Systems, Pusan National University, Pusan, Korea, in 2006 and 2010, respectively. Since 1990, he has been working as a Chief Research Engineer for LG Electronics Inc. His current research interests inlclude motor drives and the control of electrical machines, power converters, and inverter air conditioners.

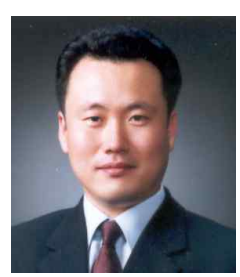

Jul-Ki Seok received his B.S., M.S., and $\mathrm{Ph} . \mathrm{D}$. in Electrical Engineering from Seoul National University, Seoul, Korea, in 1992, 1994, and 1998, respectively. From 1998 to 2001, he was a Senior Engineer with the Production Engineering Center, Samsung Electronics, Suwon, Korea. Since 2001, he has been a member of the faculty of the School of Electrical Engineering, Yeungnam University, 
Gyeongsan, Korea, where he is currently a Professor. His current research interests include motor drives, power converter control of offshore wind farms, and nonlinear system identification related to the power electronics field. Dr. Seok is currently a member of the Editorial Board of the IET Transactions on Electric Power Applications. He also serves as the Chair of the IEEE IAS-Industrial Drive Committee (IDC) Paper Award Department and an Associate Editor of the IEEE Transactions on Industry Applications. 